\title{
The influence of family history and histological stratification on breast cancer risk in women with benign breast disease: a meta-analysis
}

\author{
Wen-Bin Zhou $\cdot$ Dan-Qing Xue $\cdot$ Xiao-An Liu $\cdot$ \\ Qiang Ding $\cdot$ Shui Wang
}

Received: 30 January 2011/Accepted: 15 March 2011/Published online: 17 April 2011

(C) The Author(s) 2011. This article is published with open access at Springerlink.com

\begin{abstract}
Purpose Benign breast disease (BBD) is an important risk factor for subsequent breast cancer. However, it is unclear whether breast cancer risk is higher in cases of atypical ductal hyperplasia (ADH) than atypical lobular hyperplasia (ALH). Furthermore, it is unclear whether family history increases risk in women with various subtypes of BBD.

Methods We searched the electronic database of PubMed for case-control studies about the subsequent breast cancer risk of BBD, and a meta-analysis was conducted.

Results Of ten inclusive studies, nine were eligible for subsequent breast cancer risk of histological subtype, including 2,340 cases and 4,422 controls, and four were eligible for investigating the influence of family history on subtypes of BBD, including 1,377 cases and 2,630 controls. Relative to non-proliferative disease (NP), all subtypes of BBD increased subsequent risk, and risk for women with $\mathrm{ALH}(\mathrm{OR}=5.14,95 \%$ CI 3.52-7.52) may be higher than for women with $\mathrm{ADH}(\mathrm{OR}=2.93,95 \%$ CI 2.16-3.97). Compared to women without family history and proliferative disease, women with a first-degree family history and atypical hyperplasia $(\mathrm{AH})$ were at highest risk $(\mathrm{OR}=4.87$, 95\% CI 2.89-8.20). Relative to women without family history, women with a first-degree family history had an increased breast cancer risk in different histological
\end{abstract}

W.-B. Zhou and D.-Q. Xue contributed equally to this work.

W.-B. Zhou · D.-Q. Xue · X.-A. Liu · Q. Ding · S. Wang (凹) Department of Breast Surgery, The First Affiliated Hospital With Nanjing Medical University, 300 Guangzhou Road, Nanjing 210029, China

e-mail: ws0801@ hotmail.com subtypes of $\mathrm{BBD}$ except for $\mathrm{AH}(\mathrm{OR}=1.39,95 \% \mathrm{CI}$ 0.82-2.37).

Conclusion This meta-analysis strongly suggested that women with $\mathrm{AH}$, especially for ALH and AH combined with a first-degree family history, were at high risk, for whom risk-reduction options should be considered.

Keywords Benign breast disease - Family history · Breast cancer risk $\cdot$ Meta-analysis

\section{Introduction}

With the increased use of mammography, more and more women are diagnosed with various subtypes of benign breast disease (BBD) (Kuzma 1969; Kalache 1981). Since $\mathrm{BBD}$ is a very important risk factor for subsequent breast cancer, it is necessary to estimate the risk of breast cancer for specific histological categories. BBD is usually subdivided into non-proliferative disease (NP), proliferative disease without atypia (PDWA), and atypical hyperplasia (AH) (Dupont and Page 1985; Gail et al. 1989; Fitzgibbons et al. 1998). AH is usually categorized into atypical ductal hyperplasia (ADH) and atypical lobular hyperplasia (ALH). Women with PDWA had a 1.5-2 times higher risk of breast cancer compared to women without BBD, while an approximately four-fold increased risk of breast cancer for AH was corroborated by previous studies (Dupont and Page 1985; Hartmann et al. 2005; Page et al. 1985; Dupont et al. 1993; London et al. 1992). However, it is unclear whether breast cancer risk is higher in cases of ADH versus ALH (Degnim et al. 2007; Kabat et al. 2010; Collins et al. 2007). Some studies (Collins et al. 2007; Kabat et al. 2010) suggested that ALH was associated with a higher risk than $\mathrm{ADH}$, so that more active management should be 
considered for women with ALH. However, breast cancer risk was similar for ADH and ALH in a Mayo cohort study (Degnim et al. 2007). Family history is also a key component of breast cancer risk assessment (Ready and Arun 2010). Women with a positive family history and a special subtype of BBD may have increased risk. However, it is still unclear whether a positive family history increases breast cancer risk in women with all subtypes of BBD (Dupont and Page 1985; London et al. 1992; Carter et al. 1988; Degnim et al. 2007).

According to American Society of Clinical Oncology (ASCO) clinical practice guideline, women at risk should be considered with optimal management, including increased screening, chemoprevention, and prophylactic surgery. For women at average risk, screening mammography should be performed every 1-2 years, while for women at high risk, screening mammography should be performed every 6-12 months (Griffin and Pearlman 2010). Although $\mathrm{AH}$ and a positive family history were associated with increased breast cancer risk, the majority of women with proliferative disease (PD) and/or a positive family history would not develop breast cancer. Thus, it is necessary to identify individuals with high breast cancer risk. The purpose of this meta-analysis was to investigate the subtype of BBD with high breast cancer risk and the influence of a positive family history on various subtypes of BBD.

\section{Methods}

Search strategy

Meta-analysis was performed as described previously (Liu et al. 2010). Relevant studies were selected by searching PubMed (updated on September 2010), using the following terms: case-control, breast cancer or breast neoplasm, and benign breast disease or proliferative disease or atypia. Two reviewers (Zhou WB and Xue DQ) independently evaluated titles and abstracts of the identified papers. References in identified articles and previous reviews were also reviewed for possible inclusion. Only those published studies in English language with full text articles were included in this meta-analysis. Studies were included if they met the following criteria: (1) the diagnosis of BBD and breast cancer was confirmed histopathologically; (2) BBD that was subdivided into NP, PDWA, and AH by biopsy; (3) a case-control study examining the association between BBD and breast cancer risk; and (4) sufficient published data for estimating an odds ratio (OR) with $95 \%$ confidence interval (CI). For overlapping studies, only the one with the largest sample numbers was selected.

\section{Data extraction}

Information was carefully extracted from all the eligible studies independently by two reviewers (Zhou WB and Xue DQ). The following variables were extracted from each study if available: first author's name, publication year, country of origin, study design, numbers of cases and controls, numbers of cases and controls in different subtypes of BBD, and numbers of cases and controls in different subtypes of BBD on family history. After disagreement was resolved by discussion, all the data were reached consensus.

\section{Statistical analysis}

Crude odds ratios with $95 \%$ confidence interval were used to assess the association between the subtypes of biopsyproved BBD and subsequent breast cancer risk. Otherwise, the association between different subtypes of BBD on

Table 1 Characteristics of case-control studies about histologic stratification included in the meta-analysis

\begin{tabular}{|c|c|c|c|c|c|c|c|c|c|c|c|}
\hline \multirow[t]{2}{*}{ Author } & \multirow[t]{2}{*}{ Population } & \multirow[t]{2}{*}{ Year } & \multirow[t]{2}{*}{ Design } & \multicolumn{4}{|l|}{ Cases } & \multicolumn{4}{|c|}{ Controls } \\
\hline & & & & Total & NP & PDWA & $\mathrm{AH}(\mathrm{ADH} / \mathrm{ALH})$ & Total & NP & PDWA & $\mathrm{AH}(\mathrm{ADH} / \mathrm{ALH})$ \\
\hline Bianchi & Italy (CSPO) & 1992 & Nested case-control & 62 & 45 & 6 & 11 & 315 & 277 & 31 & 7 \\
\hline McDivitt & USA (CSHS) & 1992 & Case-control & 417 & 227 & 124 & 66 & 248 & 154 & 68 & 26 \\
\hline Stark & USA (Mayo) & 2000 & Nested case-control & 137 & 98 & 34 & $5(5 / 0)$ & 156 & 115 & 37 & $4(4 / 0)$ \\
\hline Byrne & USA (BCDDP) & 2001 & Nested case-control & 318 & 62 & 198 & 58 & 358 & 94 & 223 & 41 \\
\hline Shaaban & British & 2002 & Case-control & 117 & 62 & 38 & $17(7 / 10)$ & 345 & 248 & 79 & $18(11 / 7)$ \\
\hline Collins & USA (Nurse) & 2007 & Nested case-control & 395 & 99 & 200 & $96(45 / 36)$ & 1,610 & 611 & 839 & $160(103 / 42)$ \\
\hline Boulos & USA (NBC) & 2008 & Nested case-control & 77 & 24 & 39 & 14 & 152 & 56 & 58 & 38 \\
\hline Worsham & USA (HFHS) & 2009 & Nested case-control & 202 & 48 & 125 & $29(22 / 10)$ & 614 & 234 & 349 & $31(22 / 9)$ \\
\hline Kabat & $\mathrm{Ca}$, USA, UK & 2010 & Nested case-control & 615 & 190 & 393 & $32(13 / 16)$ & 624 & 250 & 362 & $12(6 / 5)$ \\
\hline
\end{tabular}

$N P$ non-proliferative, $P D W A$ proliferative disease without atypia, $A H$ atypical hyperplasia, $A D H$ atypical ductal hyperplasia, $A L H$ atypical lobular hyperplasia 
family history and subsequent breast cancer risk was also evaluated. The between-study heterogeneity was tested with $Q$ statistics (Lau et al. 1997). If $P<0.10$, the between-study heterogeneity was considered to be significant. When between-study heterogeneity was absent, the fixed-effects model (the Mantel-Haenszel method) (Mantel and Haenszel 1959) was used to calculate the pooled OR. Otherwise, a random-effects model (the DerSimonian and Laird method) (DerSimonian and Laird 1986) was selected. Publication bias was investigated by funnel plot, in which the standard error of $\log (\mathrm{OR})$ of each study was plotted against its $\log (\mathrm{OR})$. Funnel plot asymmetry was assessed by the method of Egger's linear regression test, a linear regression approach to measure funnel plot asymmetry on the natural logarithm scale of the OR. The significance of the intercept was determined by the $t$ test as suggested by Egger, and a $P$ value less than 0.05 was considered significant (Egger et al. 1997). All analyses were performed using the software Stata version 11.0 (Stata Corporation, College Station, TX, USA).

\section{Results}

Eligible studies

Ten case-control studies were included in this metaanalysis. Of the ten studies, eight were nested within large cohort studies (Table 1). As shown in Table 1, compared to NP, nine studies (Kabat et al. 2010; Stark et al. 2000; Boulos et al. 2008; McDivitt et al. 1992; Shaaban et al. 2002; Worsham et al. 2009; Collins et al. 2007; Byrne et al. 2001; Bianchi et al. 1992) were eligible for subsequent breast cancer risk of PDWA and AH, including 2340 cases and 4422 controls. Of the nine studies, subsequent breast cancer risk of ADH was reported in five studies (Stark et al. 2000; Shaaban et al. 2002; Collins et al. 2007; Worsham et al. 2009; Kabat et al. 2010), and subsequent breast cancer risk of ALH was reported in four studies (Shaaban et al. 2002; Collins et al. 2007; Worsham et al. 2009; Kabat et al. 2010). As shown in Table 2, four studies (Kabat et al. 2010; Dupont et al. 1993; McDivitt et al. 1992; Collins et al. 2006) were eligible for investigating the interplay between BBD (NP and PD) and a first-degree family history of breast cancer, including 1,377 cases and 2,630 controls. Of the four studies, three studies (Dupont et al. 1993; McDivitt et al. 1992; Collins et al. 2006) reported the interplay between the subtypes of PD and a first-degree family history.

Meta-analysis

Table 3 showed the main results of this meta-analysis. Relative to NP, the OR for PDWA was 1.44 (95\% CI

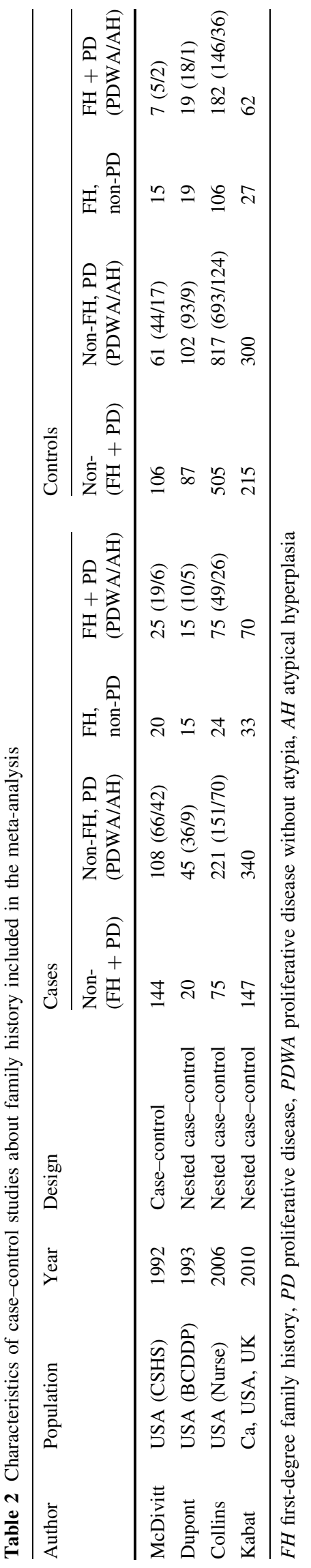


Table 3 Summary ORs and 95\% CI of subsequent breast cancer risk

$N P$ non-proliferative disease, $P D$ proliferative disease, $P D W A$ proliferative disease without atypia, $A H$ atypical hyperplasia, $A D H$ atypical ductal hyperplasia, $A L H$ atypical lobular hyperplasia

* Estimates for random-effects model

Fig. 1 Forest plot for metaanalysis of breast cancer risk from BBD for women with atypical ductal hyperplasia compared to non-proliferative disease. The width of the horizontal line represents the $95 \%$ CI of the individual studies, and the square proportional represents the weight of each study. The diamond represents the pooled OR and $95 \% \mathrm{CI}$

\begin{tabular}{llllc}
\hline Modifying factor & Histology & Odds ratio & $95 \%$ CI & $\begin{array}{c}P \text { value for } \\
\text { heterogeneity }\end{array}$ \\
\hline Histology & & & & \\
& NP & 1.00 & Reference & \\
& PDWA & 1.44 & $1.28-1.63$ & 0.80 \\
FH & 2.81 & $1.91-4.12$ & $<0.01 *$ \\
Family history & ADH & 2.93 & $2.16-3.97$ & 0.48 \\
Absent & ALH & 5.14 & $3.52-7.52$ & 0.98 \\
& & & & \\
& NP & 1.00 & Reference & \\
Present & PD & 1.67 & $1.41-1.97$ & 0.57 \\
& PDWA & 1.39 & $1.10-1.75$ & 0.48 \\
& AH & 3.10 & $2.27-4.25$ & 0.11 \\
& NP & 1.64 & $1.21-2.22$ & 0.16 \\
& PD & 2.30 & $1.80-2.94$ & 0.20 \\
& PDWA & 2.35 & $1.66-3.33$ & 0.93 \\
& AH & 4.87 & $2.89-8.20$ & 0.26 \\
\hline
\end{tabular}

\section{ADH/NP}
Study
OR $(95 \% \mathrm{Cl}) \quad$ Weight
ID

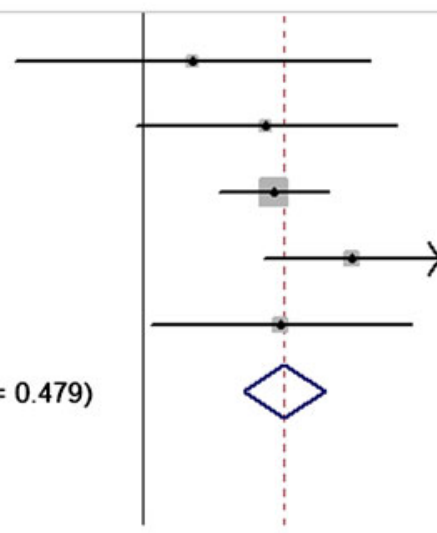

$4.47(0.38,5.61) \quad 8.23$

$2.55(0.95,6.83) 9.69$

$2.70(1.79,4.06) 55.40$

Colloins (2007)

Worsham (2009)

Kabat (2010)

$4.88(2.50,9.50) \quad 15.10$

$2.85(1.06,7.64) 11.58$

Overall (I-squared $=0.0 \%, p=0.479$ )

$2.93(2.16,3.97) \quad 400.00$
1.28-1.63, $P=0.80$ for heterogeneity); while two studies published in 1992 were excluded, the OR for PDWA was 1.48 (95\% CI 1.30-1.69, $P=0.73$ for heterogeneity); for AH, OR was 2.81 (95\% CI 1.91-4.12, $P<0.01$ for heterogeneity); while two studies published in 1992 were excluded, the OR for AH was 2.72 (95\% CI 1.83-4.04, $P=0.01$ for heterogeneity); for ADH, OR was $2.93(95 \%$ CI 2.16-3.97, $P=0.48$ for heterogeneity) (Fig. 1); for ALH, OR was 5.14 (95\% CI 3.52-7.52, $P=0.98$ for heterogeneity) (Fig. 2).

Family history was an independent risk factor in this meta-analysis. When the women without a first-degree family history and PD were used as reference group, women with a first-degree family history and $\mathrm{AH}$ had a highest risk (Table 3$)(\mathrm{OR}=4.87,95 \%$ CI 2.89-8.20, $P=0.26$ for heterogeneity).

When the women in different histological subtypes without a first-degree family history were used as reference group, a first-degree family history did not increase risk in women with $\mathrm{AH}(\mathrm{OR}=1.39,95 \% \mathrm{CI} 0.82-2.37, P=0.53$ for heterogeneity). However, a first-degree family history increased risk in women with other histological subtypes. Relative to women without family history, for NP, the OR for women with family history was $1.64(95 \%$ CI 1.21-2.22, $P=0.16$ for heterogeneity) (Fig. 3); for PD, the OR for women with family history was $1.35(95 \% \mathrm{CI}$ 
Fig. 2 Forest plot for metaanalysis of breast cancer risk from BBD for women with atypical lobular hyperplasia compared to non-proliferative disease. The width of the horizontal line represents the 95\% CI of the individual studies, and the square proportional represents the weight of each study. The diamond represents the pooled OR and $95 \% \mathrm{CI}$
Study
ALH/NP
ID

OR $(95 \% \mathrm{Cl})$

Weight

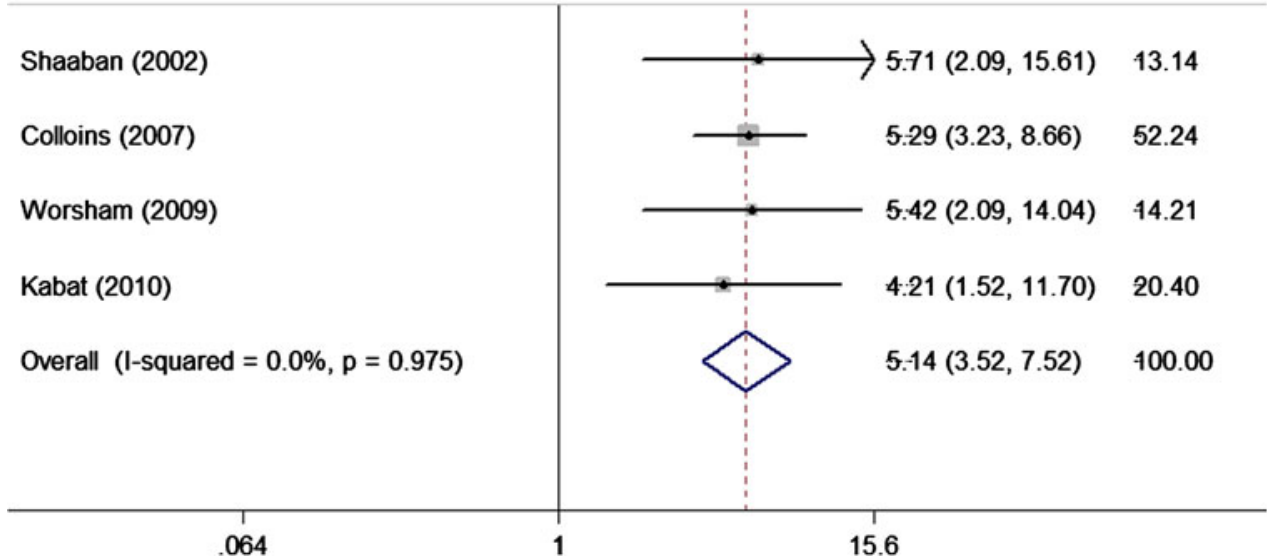

Study

$\%$

Forest plot for metaanalysis of breast cancer risk from non-proliferative disease for women with a first-degree family history compared to women without family history. The width of the horizontal line represents the $95 \%$ CI of the individual studies, and the square proportional represents the weight of each study. The diamond represents the pooled OR and $95 \% \mathrm{CI}$

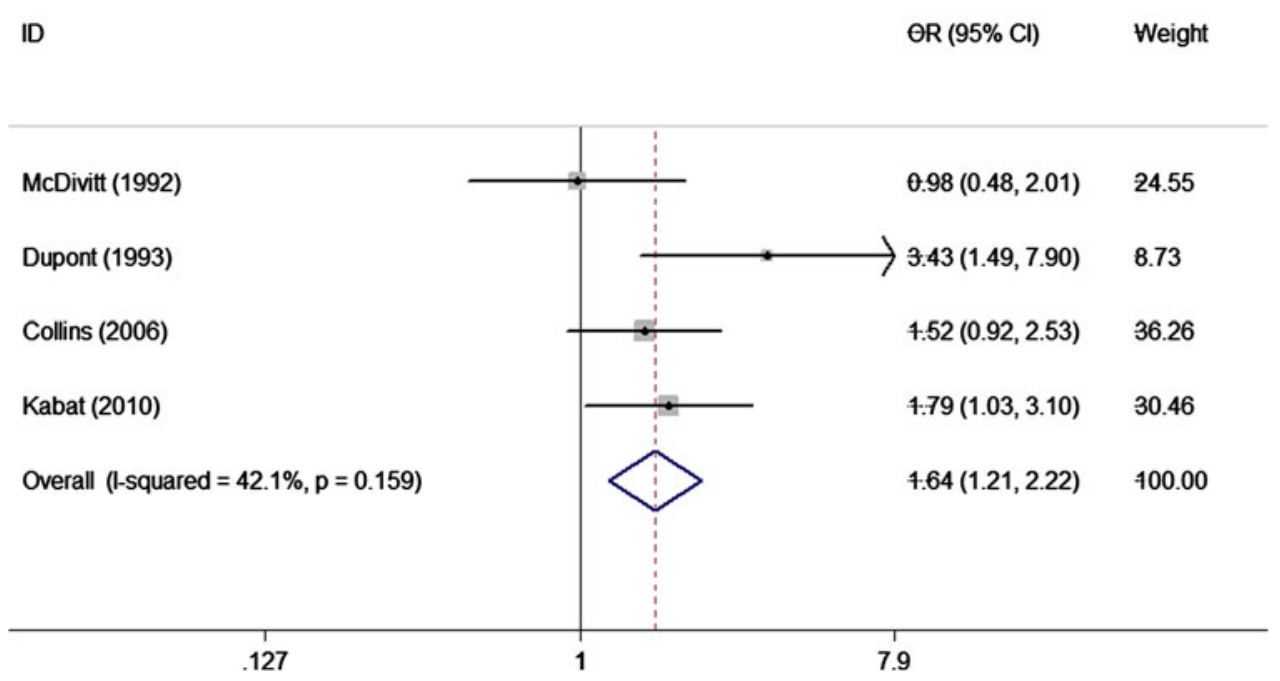

1.09-1.69, $P=0.22$ for heterogeneity) (Fig. 4); and for PDWA, the OR for women with family history was 1.61 (95\% CI 1.17-2.22, $P=0.66$ for heterogeneity).

Funnel plot and Egger's test were performed to access the publication bias of literatures. In overall studies, no significant publication bias $(P>0.05)$ existed (data not shown).

\section{Discussion}

The present meta-analysis was conducted to investigate the subtype of BBD with high breast cancer risk and the influence of a positive family history on various subtypes of BBD. This study showed that all subtypes of BBD increased the subsequent breast cancer risk, and ALH had a highest risk. Furthermore, our results suggested that a firstdegree family history increased risk in women with NP and PD. Although compared to women without family history and $\mathrm{PD}$, women with a first-degree family history and $\mathrm{AH}$ had the highest risk; a first-degree family history did not increase risk in women with $\mathrm{AH}$. Increased screening, chemoprevention, and even prophylactic surgery should be considered for women with ALH or women with a firstdegree family history and $\mathrm{AH}$.

Consistent with previous studies, our study showed that PDWA had a slightly increased risk $(\mathrm{OR}=1.44,95 \% \mathrm{CI}$ 1.28-1.63) of breast cancer, and AH had a substantially 
Fig. 4 Forest plot for metaanalysis of breast cancer risk from proliferative disease for women with a first-degree family history compared to women without family history. The width of the horizontal line represents the $95 \% \mathrm{CI}$ of the individual studies, and the square proportional represents the weight of each study. The diamond represents the pooled OR and $95 \% \mathrm{CI}$
Study

$\%$

ID

OR $(95 \% \mathrm{Cl})$

Weight

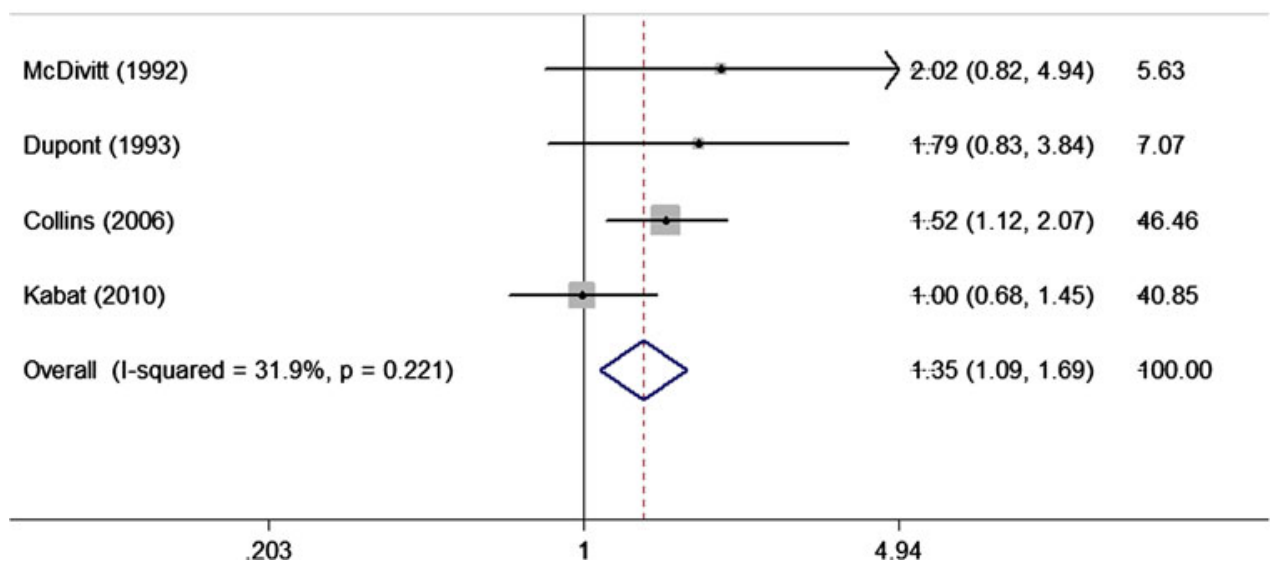

increased risk $(\mathrm{OR}=2.81,95 \%$ CI 1.91-4.12). Worsham et al. (2007) suggested that breast cancer risk from BBD for women with ADH may be higher than for women with ALH. However, the opposite results were reported in other studies (Fitzgibbons et al. 1998; Kabat et al. 2010; Collins et al. 2007). This meta-analysis suggested that breast cancer risk from BBD for women with ALH (OR $=5.14,95 \%$ CI 3.52-7.52) may be higher than for women with $\mathrm{ADH}$ $(\mathrm{OR}=2.93,95 \%$ CI 2.16-3.97). Previous study (Hartmann et al. 2005) showed that degree of family history was an independent risk factor. The risk ratio of breast cancer for NP women with a weak family history was 1.12 , but no significant difference was observed. The women with a first-degree family history were included in this study for investigating the interplay between BBD and family history of breast cancer, and the first-degree family history was a significant risk factor for women with different histological subtypes of BBD except for $\mathrm{AH}$. The future large study should be carried out to evaluate the breast cancer risk for women with different degrees of family history.

Recommendations for breast cancer screening and riskreduction options for women at average risk were different from women at high risk (Griffin and Pearlman 2010). Routine mammography should be performed for women at average risk, but no special risk-reduction management should be done (Griffin and Pearlman 2010; Meissner et al. 2011). However, increased screening, chemoprevention, and prophylactic surgery should be considered for women at high risk. This meta-analysis suggested that women with $\mathrm{AH}$, especially for ALH and $\mathrm{AH}$ combined with a firstdegree family history, were at high risk, so that riskreduction options should be considered.

Several issues may affect the efficiency of specific types of BBD with risk of breast cancer. First, the reference group used to examine the subsequent breast cancer risk among women with BBD was variant in different studies. The general population was used as reference group in some studies (Hartmann et al. 2005; Carter et al. 1988; McDivitt et al. 1992; Degnim et al. 2007), while NP was used in others (Dupont and Page 1985; London et al. 1992; Marshall et al. 1997; Worsham et al. 2009; Jacobs et al. 1999). In this meta-analysis, NP was used as reference group for calculation although data were extracted from studies with different reference groups. Therefore, this study gave a more precise estimation of the risk from a large sample. Second, there was no pathological review in some studies (Wang et al. 2004), and the classification of BBD was unequal in different centers (King et al. 2000; Patterson et al. 2004). However, the breast lesions included in this meta-analysis were all biopsy-proved BBD and reviewed by experienced pathologists.

On the other hand, some limitations still exist in this meta-analysis. First, both very old and relatively new studies were included in this study; the methodological limitation of this analysis should be considered. Second, of these ten studies, most subjects were Caucasians, including some African-Americans, while no Asians were included. Therefore, the conclusion in Asian populations was still unclear. Third, the present results were based on unadjusted ORs, and more precise estimation may be adjusted by other potential covariates.

In conclusion, this meta-analysis strongly suggested that women with $\mathrm{AH}$, especially for $\mathrm{ALH}$ and $\mathrm{AH}$ combined with a first-degree family history, were at high risk. So risk-reduction options should be considered for these women. Further study with larger sample size is necessary to get more precise estimation of breast cancer risk after diagnosis of BBD. 
Acknowledgments This report was supported in part by the National Natural Science Foundation of China (30740076), the Six Kinds of Outstanding Talent Foundation of Jiangsu Province (06-B069), the Science and Education for Health Foundation of Jiangsu Province (RC2007054), and the Natural Science Foundation of Jiangsu Province (BK2008476, BK2009438, and BK2010581).

Conflict of interest None declared.

Open Access This article is distributed under the terms of the Creative Commons Attribution Noncommercial License which permits any noncommercial use, distribution, and reproduction in any medium, provided the original author(s) and source are credited.

\section{References}

Bianchi SDTM, Simoncini R, Distante V, Russo A, Palli D (1992) Histological pattern of benign breast disease as a risk factor for invasive breast cancer. Cancer Detect Prev 16:17-19

Boulos FI, Dupont WD, Simpson JF, Schuyler PA, Sanders ME, Freudenthal ME, Page DL (2008) Histologic associations and long-term cancer risk in columnar cell lesions of the breast: a retrospective cohort and a nested case-control study. Cancer 113(9):2415-2421. doi:10.1002/cncr.23873

Byrne C, Schairer C, Brinton LA, Wolfe J, Parekh N, Salane M, Carter C, Hoover R (2001) Effects of mammographic density and benign breast disease on breast cancer risk (United States). Cancer Causes Control 12(2):103-110

Carter CL, Corle DK, Micozzi MS, Schatzkin A, Taylor PR (1988) A prospective study of the development of breast cancer in 16,692 women with benign breast disease. Am J Epidemiol 128(3): 467-477

Collins LC, Baer HJ, Tamimi RM, Connolly JL, Colditz GA, Schnitt SJ (2006) The influence of family history on breast cancer risk in women with biopsy-confirmed benign breast disease: results from the Nurses' Health Study. Cancer 107(6):1240-1247. doi: $10.1002 /$ cncr.22136

Collins LC, Baer HJ, Tamimi RM, Connolly JL, Colditz GA, Schnitt SJ (2007) Magnitude and laterality of breast cancer risk according to histologic type of atypical hyperplasia: results from the nurses' health study. Cancer 109(2):180-187. doi:10.1002/ cncr.22408

Degnim AC, Visscher DW, Berman HK, Frost MH, Sellers TA, Vierkant RA, Maloney SD, Pankratz VS, de Groen PC, Lingle WL, Ghosh K, Penheiter L, Tlsty T, Melton LJ III, Reynolds CA, Hartmann LC (2007) Stratification of breast cancer risk in women with atypia: a Mayo cohort study. J Clin Oncol 25(19):2671-2677. doi:10.1200/JCO.2006.09.0217

DerSimonian R, Laird N (1986) Meta-analysis in clinical trials. Control Clin Trials 7(3):177-188. doi:0197-2456(86)90046-2

Dupont WD, Page DL (1985) Risk factors for breast cancer in women with proliferative breast disease. N Engl J Med 312(3):146-151. doi:10.1056/NEJM198501173120303

Dupont WD, Parl FF, Hartmann WH, Brinton LA, Winfield AC, Worrell JA, Schuyler PA, Plummer WD (1993) Breast cancer risk associated with proliferative breast disease and atypical hyperplasia. Cancer 71(4):1258-1265

Egger M, Davey Smith G, Schneider M, Minder C (1997) Bias in meta-analysis detected by a simple, graphical test. BMJ 315(7109):629-634

Fitzgibbons PL, Henson DE, Hutter RV (1998) Benign breast changes and the risk for subsequent breast cancer: an update of the 1985 consensus statement. Cancer committee of the college of
American pathologists. Arch Pathol Lab Med 122(12): 1053-1055

Gail MH, Brinton LA, Byar DP, Corle DK, Green SB, Schairer C, Mulvihill JJ (1989) Projecting individualized probabilities of developing breast cancer for white females who are being examined annually. J Natl Cancer Inst 81(24):1879-1886

Griffin JL, Pearlman MD (2010) Breast cancer screening in women at average risk and high risk. Obstet Gynecol 116(6):1410-1421. doi:10.1097/AOG.0b013e3181fe714e

Hartmann LC, Sellers TA, Frost MH, Lingle WL, Degnim AC, Ghosh K, Vierkant RA, Maloney SD, Pankratz VS, Hillman DW, Suman VJ, Johnson J, Blake C, Tlsty T, Vachon CM, Melton LJ III, Visscher DW (2005) Benign breast disease and the risk of breast cancer. N Engl J Med 353(3):229-237. doi:10.1056/ NEJMoa044383

Jacobs TW, Byrne C, Colditz G, Connolly JL, Schnitt SJ (1999) Radial scars in benign breast-biopsy specimens and the risk of breast cancer. N Engl J Med 340(6):430-436. doi:10.1056/ NEJM199902113400604

Kabat GC, Jones JG, Olson N, Negassa A, Duggan C, Ginsberg M, Kandel RA, Glass AG, Rohan TE (2010) A multi-center prospective cohort study of benign breast disease and risk of subsequent breast cancer. Cancer Causes Control 21(6):821-828. doi:10.1007/s10552-010-9508-7

Kalache A (1981) Risk factors for breast cancer: a tabular summary of the epidemiological literature. Br J Surg 68(11):797-799

King TA, Scharfenberg JC, Smetherman DH, Farkas EA, Bolton JS, Fuhrman GM (2000) A better understanding of the term radial scar. Am J Surg 180(6):428-432. doi:S0002-9610(00)00506-7 (discussion 432-423)

Kuzma JF (1969) Carcinoma-in situ of the breast. J Fla Med Assoc 56(12):905-906

Lau J, Ioannidis JP, Schmid CH (1997) Quantitative synthesis in systematic reviews. Ann Intern Med 127(9):820-826

Liu X, Wang Z, Yu J, Lei G, Wang S (2010) Three polymorphisms in interleukin-1beta gene and risk for breast cancer: a metaanalysis. Breast Cancer Res Treat 124(3):821-825. doi:10.1007/ s10549-010-0910-3

London SJ, Connolly JL, Schnitt SJ, Colditz GA (1992) A prospective study of benign breast disease and the risk of breast cancer. JAMA 267(7):941-944

Mantel N, Haenszel W (1959) Statistical aspects of the analysis of data from retrospective studies of disease. J Natl Cancer Inst 22(4):719-748

Marshall LM, Hunter DJ, Connolly JL, Schnitt SJ, Byrne C, London SJ, Colditz GA (1997) Risk of breast cancer associated with atypical hyperplasia of lobular and ductal types. Cancer Epidemiol Biomarkers Prev 6(5):297-301

McDivitt RW, Stevens JA, Lee NC, Wingo PA, Rubin GL, Gersell D (1992) Histologic types of benign breast disease and the risk for breast cancer. The cancer and steroid hormone study group. Cancer 69(6):1408-1414

Meissner HI, Klabunde CN, Han PK, Benard VB, Breen N (2011) Breast cancer screening beliefs, recommendations and practices: primary care physicians in the united states. Cancer. doi:10.1002/cncr.25873

Page DL, Dupont WD, Rogers LW, Rados MS (1985) Atypical hyperplastic lesions of the female breast. A long-term follow-up study. Cancer 55(11):2698-2708

Patterson JA, Scott M, Anderson N, Kirk SJ (2004) Radial scar, complex sclerosing lesion and risk of breast cancer. Analysis of 175 cases in Northern Ireland. Eur J Surg Oncol 30(10): 1065-1068. doi:10.1016/j.ejso.2004.08.004

Ready K, Arun B (2010) Clinical assessment of breast cancer risk based on family history. J Natl Compr Canc Netw 8(10):1148-1155. doi:8/10/1148 
Shaaban AM, Sloane JP, West CR, Moore FR, Jarvis C, Williams EM, Foster CS (2002) Histopathologic types of benign breast lesions and the risk of breast cancer: case-control study. Am J Surg Pathol 26(4):421-430

Stark A, Hulka BS, Joens S, Novotny D, Thor AD, Wold LE, Schell MJ, Melton LJ III, Liu ET, Conway K (2000) HER-2/neu amplification in benign breast disease and the risk of subsequent breast cancer. J Clin Oncol 18(2):267-274

Wang J, Costantino JP, Tan-Chiu E, Wickerham DL, Paik S, Wolmark N (2004) Lower-category benign breast disease and the risk of invasive breast cancer. J Natl Cancer Inst 96(8):616-620
Worsham MJ, Abrams J, Raju U, Kapke A, Lu M, Cheng J, Mott D, Wolman SR (2007) Breast cancer incidence in a cohort of women with benign breast disease from a multiethnic, primary health care population. Breast J 13(2):115-121. doi:10.1111/j. 1524-4741.2007.00388.x

Worsham MJ, Raju U, Lu M, Kapke A, Botttrell A, Cheng J, Shah V, Savera A, Wolman SR (2009) Risk factors for breast cancer from benign breast disease in a diverse population. Breast Cancer Res Treat 118(1):1-7. doi:10.1007/s10549-008-0198-8 